Provided for non-commercial research and education use. Not for reproduction, distribution or commercial use.

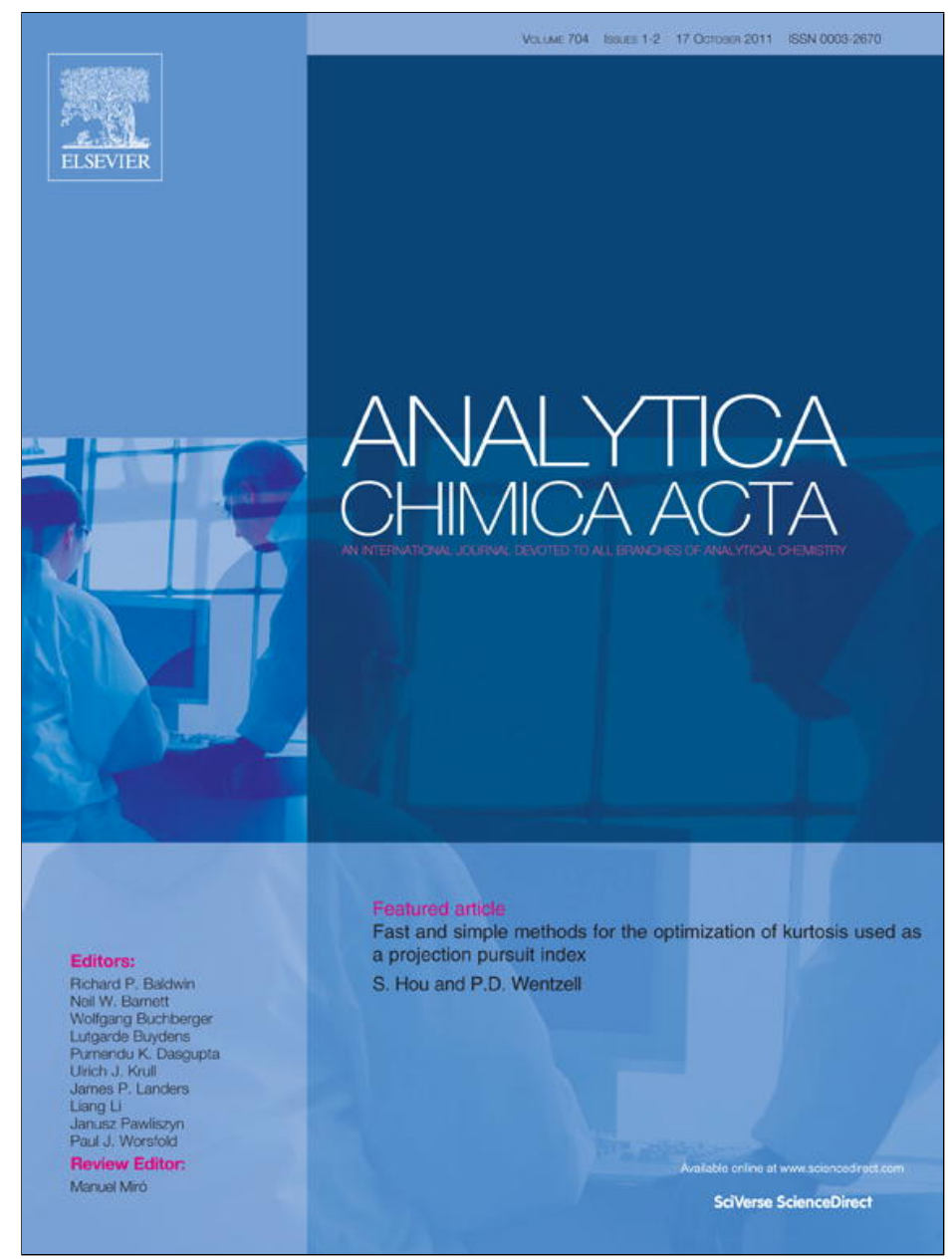

This article appeared in a journal published by Elsevier. The attached copy is furnished to the author for internal non-commercial research and education use, including for instruction at the authors institution and sharing with colleagues.

Other uses, including reproduction and distribution, or selling or licensing copies, or posting to personal, institutional or third party websites are prohibited.

In most cases authors are permitted to post their version of the article (e.g. in Word or Tex form) to their personal website or institutional repository. Authors requiring further information regarding Elsevier's archiving and manuscript policies are encouraged to visit:

http://www.elsevier.com/copyright 


\title{
Potentiometric flow injection system for determination of reductants using a polymeric membrane permanganate ion-selective electrode based on current-controlled reagent delivery
}

\author{
Wenjing Song a,b, Jiawang Ding ${ }^{\mathrm{a}}$, Rongning Liang ${ }^{\mathrm{a}}$, Wei Qin ${ }^{\mathrm{a}, *}$ \\ a CAS and Shandong Provincial Key Laboratory of Coastal Zone Environmental Processes, Yantai Institute of Coastal Zone Research, \\ Chinese Academy of Sciences, Yantai 264003, PR China \\ ${ }^{\mathrm{b}}$ Graduate University of the Chinese Academy of Sciences, Beijing 100049, PR China
}

\section{A R T I C L E I N F O}

\section{Article history:}

Received 16 June 2011

Received in revised form 24 July 2011

Accepted 2 August 2011

Available online 10 August 2011

\section{Keywords:}

Potentiometry

Flow injection analysis

Ion-selective electrodes

Reductants

Current-controlled release

\begin{abstract}
A B S T R A C T
A polymeric membrane permanganate-selective electrode has been developed as a current-controlled reagent release system for potentiometric detection of reductants in flow injection analysis. By applying an external current, diffusion of permanganate ions across the polymeric membrane can be controlled precisely. The permanganate ions released at the sample-membrane interface from the inner filling solution of the electrode are consumed by reaction with a reductant in the sample solution thus changing the measured membrane potential, by which the reductant can be sensed potentiometrically. Ascorbate, dopamine and norepinephrine have been employed as the model reductants. Under the optimized conditions, the potential peak heights are proportional to the reductant concentrations in the ranges of $1.0 \times 10^{-5}$ to $2.5 \times 10^{-7} \mathrm{M}$ for ascorbate, of $1.0 \times 10^{-5}$ to $5.0 \times 10^{-7} \mathrm{M}$ for dopamine, and of $1.0 \times 10^{-5}$ to $5.0 \times 10^{-7} \mathrm{M}$ for norepinephrine, respectively with the corresponding detection limits of $7.8 \times 10^{-8}$, $1.0 \times 10^{-7}$ and $1.0 \times 10^{-7} \mathrm{M}$. The proposed system has been successfully applied to the determination of reductants in pharmaceutical preparations and vegetables, and the results agree well with those of iodimetric analysis.
\end{abstract}

(C) 2011 Elsevier B.V. All rights reserved.

\section{Introduction}

Flow injection analysis (FIA) coupled with potentiometric ionselective electrodes (ISEs) has attracted considerable interest in analytical chemistry and biochemistry owing to its desirable characteristics, such as low consumption of reagents, high sample throughput, simple automated operation, and possibility of on-line sample pretreatment $[1,2]$. Conventional potentiometric FIA systems exploit direct measurements of analyte ions using the ISEs [3-6]. To extend the applications of ISEs in FIA, the indirect sensing mode has been developed based on the complexing [7-9] and redox [10-12] properties of indicator ions. Many analytes can be indirectly measured by potentiometrically monitoring the reduction of indicator ions which are added in the carrier solution. Although these approaches have made great contributions toward the potentiometric detection in FIA, there are some inherent disadvantages including peak broadening resulting from the excessive volume introduced by the reaction coil and slow electrode response [13]. Metallic copper electrodes have been applied successfully to FIA

\footnotetext{
* Corresponding author. Tel.: +86 535210 9156; fax: +86 535210900.

E-mail address: wqin@yic.ac.cn (W. Qin).
}

for potentiometric detection of copper complexing ligands such as amino acids, phosphates, cyanide, sulfite, halides, and thiocyanate in the sample zone without addition of indicator ions to the system, for which copper ions are spontaneously released from the electrode surface [14-16]. Unfortunately, the metal electrodes suffer from the problem of rapid poisoning by complexing agents.

Recently, a promising potentiometric detection approach that makes use of zero-current ion fluxes through an ISE membrane (i.e. fluxes in the direction of the sample solution) has been developed for measuring a wide range of analytes which can decrease the concentrations of the indicator ions released at the samplemembrane phase boundary via complexing [17], redox [18] or enzyme-catalyzed reactions [19-21]. Such an ISE membrane not only serves as a polymer matrix for reagent release, but also works as a transducer for sensitive potentiometric detection, making the ISE membrane very attractive for sensor miniaturization. Herein, we describe our initial efforts to extend the application of this novel ISE detection method to FIA. An external current at the microampere scale is applied across the ISE membrane for rapid and precise release of indicator ions. It will be shown that such an ISE with current-controlled reagent delivery can offer a rapid and continuous way for measuring analytes in hydrodynamic conditions. 
As a proof-of-concept experiment, a ligand-free permanganate ISE based on an anion exchanger tridodecylmethylammonium chloride [18] is prepared for analysis of reductants. Reductants such as ascorbate, dopamine, and norepinephrine can be measured by oxidation with permanganate released continuously from the inner reference solution of the membrane ISE, which increases the ISE potential due to the consumption of permanganate at the samplemembrane interface. The designed method allows sensitive and reproducible detection of reductants in FIA.

\section{Experimental}

\subsection{Reagents and solutions}

Ascorbate was obtained from Sinopharm Chemical Reagent Co., Ltd. (Shanghai, China), dopamine was from Acros Organics (New Jersey, USA), and norepinephrine was supplied by Sigma (St. Louis, USA). $0.02 \mathrm{M}$ sodium citrate of $\mathrm{pH} 8.6$ deoxygenated by nitrogen was used as the carrier solution. A stock solution of $0.01 \mathrm{M}$ for each reductant was prepared with the carrier solution. Testing standard solutions were prepared by appropriate dilution of the stock solution with the carrier solution. All the solutions were prepared daily and stored in dark.

Tridodecylmethylammonium chloride (TDMAC), 2-nitrophenyl octyl ether (o-NPOE), and high molecular weight poly(vinyl chloride) (PVC) were purchased from Fluka AG (Buchs, Switzerland). All other chemicals and reagents were of Selectophore or analytical reagent grade. Aqueous solutions were prepared with freshly deionized water (18.2 $\mathrm{M} \Omega \mathrm{cm}$ specific resistance) obtained with a Pall Cascada laboratory water system.

\subsection{Apparatus}

Potentiometric measurements were performed with a CHI-760C electrochemical workstation (Shanghai, China). The FIA system consisted of a peristaltic pump $\left(0.44 \mathrm{~mL} \mathrm{~min}^{-1}\right)$, a sample injection valve $(100 \mu \mathrm{L}$ loop) and a thin-layer flow cell $(60 \mu \mathrm{L})$. The detection chamber was constructed in-house from a single block of Perspex, which has a three-electrode system. A permanganateselective working electrode (i.d. $6 \mathrm{~mm}$, o.d. $9 \mathrm{~mm}$ ) and a platinum disk counter electrode (i.d. $5 \mathrm{~mm}$, o.d. $9 \mathrm{~mm}$ ) were imbedded into the cell body face to face, with a distance of $1 \mathrm{~mm}$. An $\mathrm{Ag} / \mathrm{AgCl}$ reference electrode (i.d. $2 \mathrm{~mm}$, o.d. $4 \mathrm{~mm}$ ) with an inner solution of $3 \mathrm{M} \mathrm{KCl}$ was placed $8 \mathrm{~mm}$ away from the working electrode at the exit of the flow cell. The whole flow-through system was assembled using Teflon tubing of a $0.8 \mathrm{~mm}$ internal diameter.

\subsection{Membranes and electrode preparation}

The ionophore-free membranes contained $10 \mathrm{wt} \%$ TDMAC, $65 \mathrm{wt} \%$ o-NPOE and $25 \mathrm{wt} \%$ PVC. Membranes of $\sim 210 \mu \mathrm{m}$ thickness were obtained by casting a solution of $\sim 360 \mathrm{mg}$ of the membrane components dissolved in $2.5 \mathrm{~mL}$ of tetrahydrofuran (THF) into a glass ring of $36 \mathrm{~mm}$ diameter fixed on a glass plate and letting the solvent evaporate overnight. Membrane thicknesses were visually measured with a CX31-32C02 Olympus microscope (Tokyo, Japan). For each working electrode, a disk of $9 \mathrm{~mm}$ diameter was punched from the membranes and glued to a plasticized PVC tube (i.d. $6 \mathrm{~mm}$, o.d. $9 \mathrm{~mm}$ ) with THF. Experimental selectivity coefficients for the permanganate-selective electrode were measured by using $0.01 \mathrm{M}$ $\mathrm{NaCl}$ as the internal filling solution. For reductant detection, $1 \mathrm{~mL}$ of $0.1 \mathrm{M}$ potassium permanganate containing $0.02 \mathrm{M} \mathrm{NaCl}$ was added to each electrode as the inner filling solution. Before measurements, all the electrodes were conditioned in a solution identical to the inner filling solution for one day.

\subsection{EMF measurements}

Potentiometric FIA measurements for reductants were carried out by applying a cathodic current of $1.0 \mu \mathrm{A}$ at $25^{\circ} \mathrm{C}$ in the galvanic cell: $\mathrm{Ag} / \mathrm{AgCl} / 3 \mathrm{M} \mathrm{KCl} / /$ sample solution/ISE membrane/inner filling solution $/ \mathrm{AgCl} / \mathrm{Ag}$. For measuring the selectivity coefficients of the ISE and the activities of the permanganate ions released at the sample-membrane interface, the EMF values were corrected for the liquid-junction potential according to the Henderson equation and the activity coefficients were calculated by the Debye-Hückel approximation.

\section{Results and discussion}

\subsection{Optimization of FIA parameters}

The effect of injected sample volume on the sensitivity of the FIA system was tested from 50 to $150 \mu \mathrm{L}$. As shown in Fig. $1 \mathrm{~A}$, the potential peak height increases rapidly with increasing the sample volume up to $100 \mu \mathrm{L}$, which is due to the fact that larger sample volumes could cause more efficient redox reactions between the reductants in the sample solution and the permanganate ions released at the surface of the ISE membrane. Fig. 1A also shows that further increasing the sample volume cannot significantly increase the detection sensitivity. Therefore, an injection volume of $100 \mu \mathrm{L}$ was employed for subsequent experiments.

The influence of flow rate was studied in the range of $0.3-1.2 \mathrm{~mL} \mathrm{~min}^{-1}$. The results are shown in Fig. 1B. It can be seen that higher flow rates result in lower potential peak heights which are due to the short duration of the redox reactions between the reductants in the sample zone and permanganate at the electrode surface. However, lower flow rates could prolong the analytical procedures. Considering a compromise between sensitivity and analysis time, a flow rate of $0.44 \mathrm{~mL} \mathrm{~min}^{-1}$ was selected.

The effect of sample $\mathrm{pH}$ on the potential response was investigated by adjusting the $\mathrm{pH}$ values of $0.1 \mathrm{M} \mathrm{NaCl}$ with $\mathrm{NaOH}$ and $\mathrm{HCl}$. As shown in Fig. 1C, the peak potential was strongly dependent on the sample $\mathrm{pH}$, with a maximum value at $\mathrm{pH} 8-10$. Under acidic conditions, manganate(VII) is reduced to $\mathrm{Mn}^{2+}$ with five electrons transferred, while under basic conditions, manganate(VII) is reduced to the +4 oxidation state of $\mathrm{MnO}_{2}$ with three electrons transferred. These redox mechanisms indicate that more permanganate ions can be consumed with the reductants at basic conditions, thus resulting in higher EMF changes. However, lower potential responses were observed at pHs higher than 10 , which is probably due to the fact that reductants are more susceptible to be oxidized by dissolved oxygen in strongly alkaline media. In this work, $0.02 \mathrm{M}$ sodium citrate of $\mathrm{pH} 8.6$ was used as the carrier solution, which is not only due to the suitable $\mathrm{pH}$ provided for the redox reactions but also to the poor lipophilicity of citrate $\left(\mathrm{Cit}^{3-}\right)[22,23]$. The influence of the discriminated ions in the carrier solution was characterized by the selectivity coefficient $\left(\log \mathrm{K}_{\mathrm{MnO}_{4}{ }^{-}, \mathrm{Cit}^{3-}}^{\mathrm{pot}}\right)$ for permanganate over $\mathrm{Cit}^{3-}$ using the method which is termed the "strong interference" method introduced by Bakker to eliminate the influence of the inherent sensitivity limit on the response toward discriminated ions $[24,25]$. The logarithmic Nikolskii coefficient $\left(\log K_{\mathrm{MnO}_{4}{ }^{-}, \mathrm{Cit}^{3-}}^{\mathrm{pot}^{3}}\right)$ was measured as $-6.74( \pm 0.09)$, which indicates a lower background for potentiometric measurements.

\subsection{Current-controlled release of permanganate ions at membrane surface}

The constant release of primary ions under zero-current conditions from inner filling solution into sample solution which dictated the detection limit of the potentiometric sensor at low sample con- 

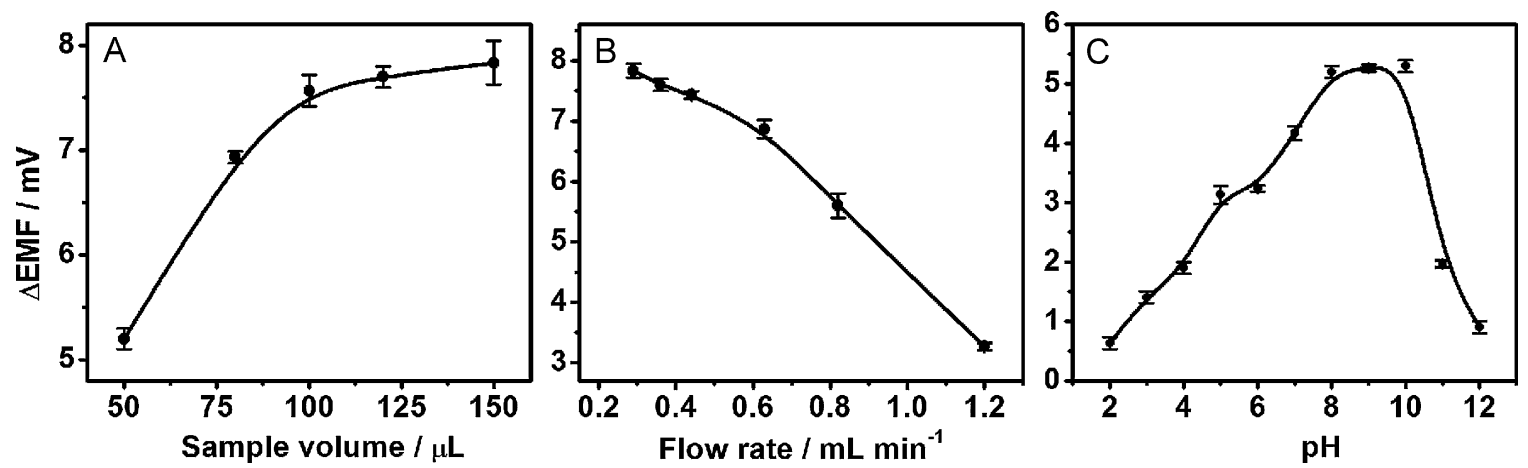

Fig. 1. Effects of $(\mathrm{A})$ injection volume, (B) flow rate and (C) sample pH on the FIA potential response to ascorbate. Unless stated otherwise, experiments were performed under the following conditions: ascorbate, $5.0 \times 10^{-6} \mathrm{M}$; carrier solution, $0.02 \mathrm{M}$ sodium citrate of pH 8.6 ; flow rate, $0.44 \mathrm{~mL}$ min ${ }^{-1}$; injection volume, $100 \mu \mathrm{L}$; applied current, $1.0 \mu \mathrm{A}$. Each data point represents a mean value \pm standard deviation for three measurements.

centrations has been extensively studied in recent years [26]. Direct evidence of permanganate fluxes across ISE membrane has been tracked by graphite stove atomic absorption spectroscopy [18]. In the present work, the amounts of released permanganate ions are modulated by applying external currents. The activities of permanganate released at the sample-membrane phase boundary with different currents were measured by calibrating with a series of permanganate solution at higher concentrations of $0.01,0.03$ and $0.1 \mathrm{M}$. The results are illustrated in Fig. 2. It can be seen that higher currents can drive larger ion fluxes from the inner filling solution into the carrier solution and therefore cause higher concentrations of permanganate ions released at the sample-membrane interface.

\subsection{Effect of applied current on the FIA potential response}

Continuous detection in hydrodynamic systems requires a short recovery time of the detector to avoid the problem of peak tailing, which not only affects the measurement of peak height but also degrades the resolution of adjacent peaks. Since the concentration of permanganate ions released at the membrane surface determines the membrane potential, the baseline can be fully recovered only if a constant release of reagent in the direction of the carrier solution is obtained shortly after detection of analyte in the flow system. The FIA responses of $5.0 \times 10^{-6} \mathrm{M}$ ascorbate under zero-current conditions and with an applied current are shown in Fig. 3. It can be seen that under zero-current conditions the spontaneous release of permanganate ions through the ISE membrane shows a large potential drift and a rather long recovery time, which cause much distorted peak shapes and a decrease in potential signals (Fig. 3A). Recently, it has been found that transportation of

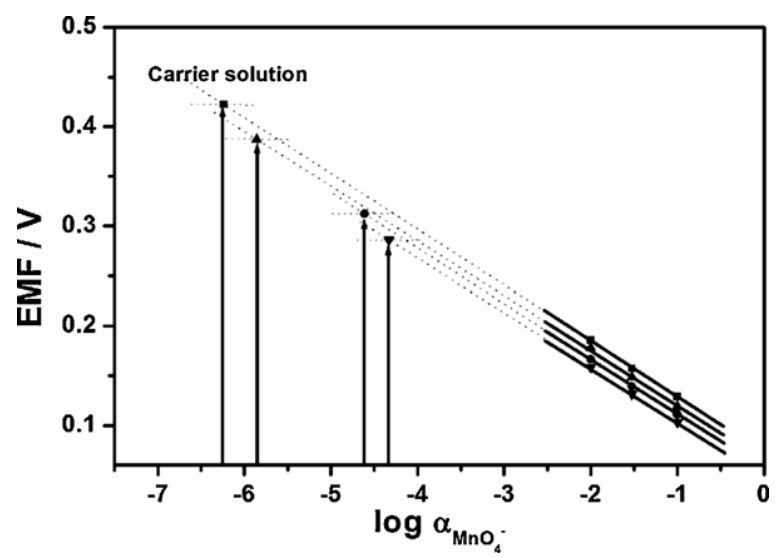

Fig. 2. Potential responses of the ISE to permanganate and the carrier solution with the applied currents of $(\boldsymbol{\square}) 0 \mu \mathrm{A},(\boldsymbol{\Delta}) 0.5 \mu \mathrm{A},(\bullet) 1.0 \mu \mathrm{A}$, and (v) $2.0 \mu \mathrm{A}$. primary ions through polymeric membranes of inner-solution ISEs can be controlled precisely by applying an external current $[21,27]$. Indeed, as shown in Fig. 3B, symmetrical peaks and stable baselines were obtained by using the current-driven strategy which could promote the diffusion of the permanganate ions through the polymeric membrane and effectively renew the reagent release at the membrane surface, thus dramatically shortening the recovery time. However, experiments also showed that higher currents applied through the ISE membrane could release larger amounts of permanganate at the sample-membrane interface, which makes the electrode insensitive to the lower concentrations of reductants (Fig. 4). For sensitive detection and rapid recovery of the membrane ISE, a current of $1.0 \mu \mathrm{A}$ was applied for controlled-release of reagent. In this case, the activity of permanganate ions released at the sample-membrane phase boundary was $2.3 \times 10^{-5} \mathrm{M}$ (Fig. 2).

\subsection{Determination of reductants}

Using the proposed potentiometric strategy, typical FIA responses for ascorbate, dopamine and norepinephrine are shown in Fig. 5 . The potential peak signals are caused by the consumption of permanganate ions released at the sample-membrane surface, other than the reductants themselves, which is confirmed by the fact that no peaks can be observed if the inner filling solution does not contain permanganate ions (data not shown).

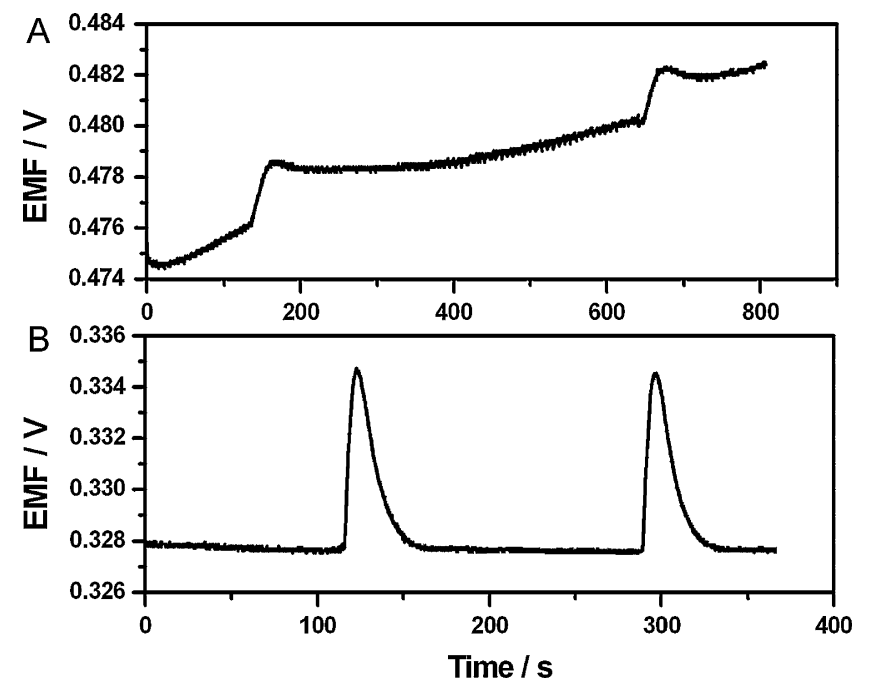

Fig. 3. Comparison of the FIA responses of $5.0 \times 10^{-6} \mathrm{M}$ ascorbate obtained using the potentiometric ISE under zero-current conditions (A) and with a cathodic current of $1.0 \mu \mathrm{A}(\mathrm{B})$. Other conditions are as in Fig. 1. 
Table 1

Working characteristics of the proposed FIA system for determination of ascorbate, dopamine and norepinephrine.

\begin{tabular}{lll}
\hline Sample & Linear range $(\mathrm{M})$ & Correlation coefficient \\
\hline Ascorbate & $1.0 \times 10^{-5}$ to $2.5 \times 10^{-7}$ & 0.9948 \\
Dopamine & $1.0 \times 10^{-5}$ to $5.0 \times 10^{-7}$ & 0.9970 \\
Norepinephrine & $1.0 \times 10^{-5}$ to $5.0 \times 10^{-7}$ & 0.9953 \\
\hline
\end{tabular}

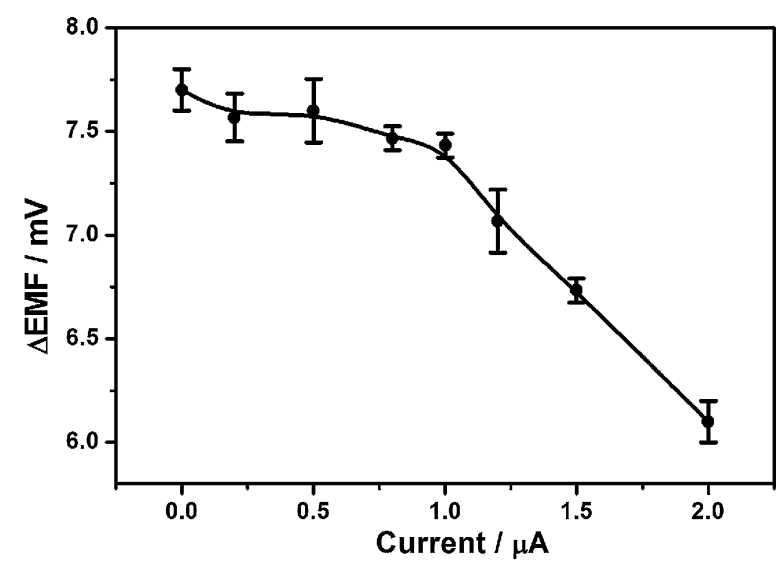

Fig. 4. Effect of applied current on the FIA potential response. Other conditions are as in Fig. 1. Each data point represents an average \pm standard deviation for three measurements.

Table 1 displays the characteristics of the established FIA system for the three reductants. It can be seen that the potential peak heights are proportional to the reductant concentrations in the ranges of $1.0 \times 10^{-5}$ to $2.5 \times 10^{-7} \mathrm{M}$ for ascorbate, of $1.0 \times 10^{-5}$ to $5.0 \times 10^{-7} \mathrm{M}$ for dopamine, and of $1.0 \times 10^{-5}$ to $5.0 \times 10^{-7} \mathrm{M}$ for norepinephrine, respectively with the corresponding detection limits $(3 \sigma)$ of $7.8 \times 10^{-8}, 1.0 \times 10^{-7}$ and $1.0 \times 10^{-7} \mathrm{M}$. The detection limits are at least one order of magnitude lower than those reported by other researchers [12,28-32]. The order of decreasing potential responses for these reductants is ascorbate >dopamine, norepinephrine, which corresponds directly to the order of their reducing powers.

The precision of the system was checked with repetitive determination of $2.5 \times 10^{-6} \mathrm{M}$ of each reductant. After six injections, the potential peak heights showed relative standard deviations of $3.1 \%, 4.2 \%$, and $3.8 \%$ for ascorbate, dopamine and norepinephrine, respectively. Sensor stability was evaluated by monitoring daily the potential peak signals of the electrode with an applied cathodic
Table 2

Tolerable concentration ratios with respect to ascorbate, dopamine and norepinephrine for some interfering species ( $<5 \%$ error).

\begin{tabular}{|c|c|c|}
\hline \multirow[t]{2}{*}{ Substance } & \multicolumn{2}{|c|}{$\begin{array}{l}\text { Tolerable } \\
\text { concentration ratio }\end{array}$} \\
\hline & Ascorbate & $\begin{array}{l}\text { Dopamine/ } \\
\text { norepinephrine }\end{array}$ \\
\hline $\begin{array}{l}\mathrm{K}^{+}, \mathrm{Na}^{+}, \mathrm{H}_{2} \mathrm{PO}_{4}^{-}, \mathrm{HPO}_{4}^{2-}, \mathrm{Cl}^{-}, \text {Amylum, } \\
\quad \text { Glucose, Sucrose, Vitamin B2, Acetic acid }\end{array}$ & $>1000$ & $>1000$ \\
\hline Oxalic acid & 1000 & 500 \\
\hline $\mathrm{NO}_{3}{ }^{-}, \beta$-cyclodextrin & 500 & 500 \\
\hline $\mathrm{Mg}^{2+}, \mathrm{Zn}^{2+}, \mathrm{Ca}^{2+}$ & 100 & 100 \\
\hline Glycine & 100 & 50 \\
\hline Dehydroascorbic acid, Tartaric acid & 1 & 0.5 \\
\hline Uric acid & 0.5 & 0.2 \\
\hline Vitamin B1 & 0.2 & 0.1 \\
\hline
\end{tabular}

current of $1.0 \mu \mathrm{A}$. The electrode was used $8 \mathrm{~h}$ per day and stored in the solution identical to the inner filling solution when not in use. Experiments showed that no significant changes were observed in the response characteristics of the polymeric membrane electrode after one week. Since permanganate ions at a high concentration of $0.1 \mathrm{M}$ was contained in the inner filling solution of the electrode, the consumption of permanganate during this period was negligible. There was no poisoning of the membrane electrode by manganese dioxide produced from the redox reactions between permanganate and reductants in the carrier solution of $\mathrm{pH}$ 8.6. This is probably due to the fact that the manganese dioxide produced is in relatively small amounts and can be dissolved and washed away by the carrier solution.

\subsection{Interferences}

Interferences of foreign substances were tested by analyzing standard solutions of ascorbate, dopamine and norepinephrine $\left(1.0 \times 10^{-6} \mathrm{M}\right)$ to which increasing amounts of interfering species were added. The tolerable concentrations of the interfering organic compounds and inorganic ions are listed in Table 2 . It can be seen that the proposed ISE shows high selectivity for determina-

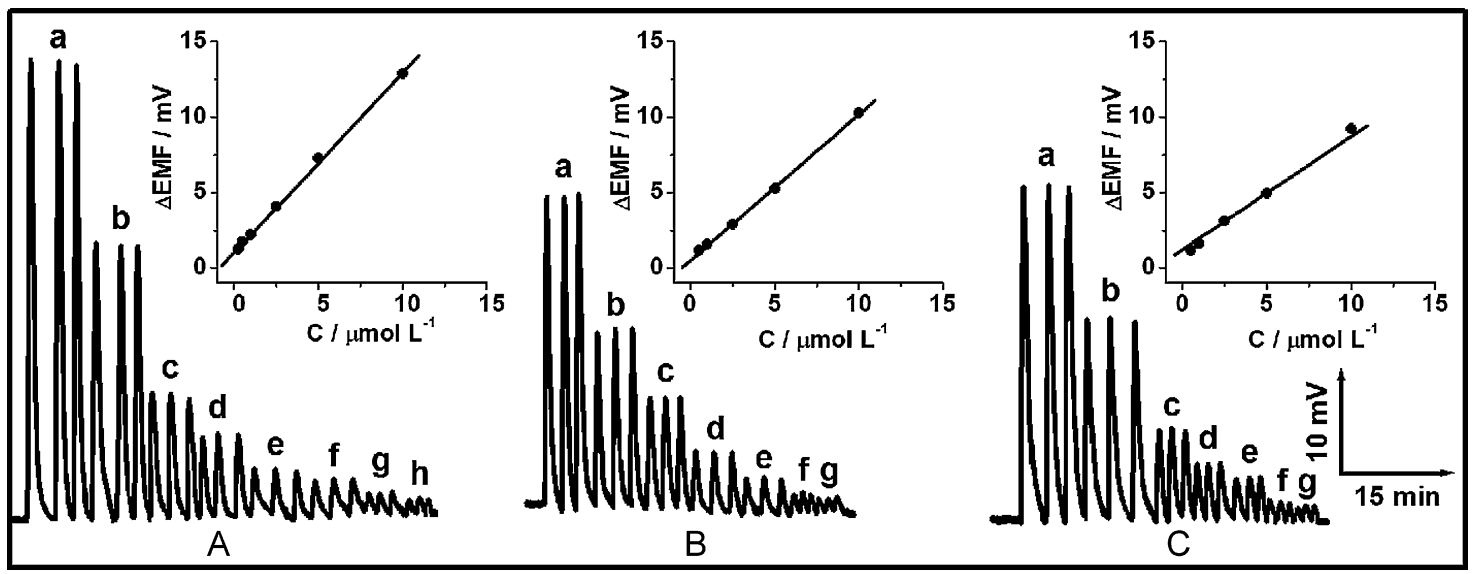

Fig. 5. FIA responses of (A) ascorbate, (B) dopamine and (C) norepinephrine at different concentrations: (a) $5.0 \times 10^{-5} \mathrm{M}$; (b) $2.5 \times 10^{-5} \mathrm{M}$; (c) $1.0 \times 10^{-5} \mathrm{M}$; (d) $5.0 \times 10^{-6} \mathrm{M}$; (e) $2.5 \times 10^{-6} \mathrm{M}$; (f) $1.0 \times 10^{-6} \mathrm{M}$; (g) $5.0 \times 10^{-7} \mathrm{M}$; (h) $2.5 \times 10^{-7} \mathrm{M}$. Insets show the calibration curves for the FIA potential responses versus the sample concentrations. Other conditions are as in Fig. 1. Each data point represents an average for three measurements. 
Table 3

Results of ascorbate, dopamine in vegetables and pharmaceutical preparations.

\begin{tabular}{|c|c|c|c|c|c|c|}
\hline \multirow[t]{2}{*}{ Sample } & \multicolumn{2}{|c|}{ Results by proposed method ${ }^{\mathrm{a}}$} & \multicolumn{3}{|c|}{ Recovery results } & \multirow[t]{2}{*}{ Results by iodimetry ${ }^{\mathrm{a}}(\mathrm{mg})$} \\
\hline & In diluted sample $(\mu \mathrm{M})$ & In real sample $(\mathrm{mg})$ & Added $(\mu \mathrm{M})$ & Found $^{\mathrm{a}}(\mu \mathrm{M})$ & $\overline{\text { Recovery (\%) }}$ & \\
\hline Mung bean sprouts & $1.24 \pm 0.10$ & $0.158 \pm 0.013 \mathrm{~g}^{-1}$ & 2.00 & $3.21 \pm 0.07$ & 99 & $0.161 \pm 0.009 \mathrm{~g}^{-1}$ \\
\hline Tomato & $2.95 \pm 0.06$ & $0.402 \pm 0.008 \mathrm{~g}^{-1}$ & 2.00 & $4.91 \pm 0.17$ & 98 & $0.395 \pm 0.011 \mathrm{~g}^{-1}$ \\
\hline Vc honeysuckle pills ${ }^{\mathrm{b}}$ & $5.66 \pm 0.22$ & $112 \pm 4 \mathrm{~g}^{-1}$ & 2.00 & $7.73 \pm 0.20$ & 104 & $113 \pm 5 \mathrm{~g}^{-1}$ \\
\hline Dopamine hydrochloride injection $^{c}$ & $1.36 \pm 0.07$ & $10.4 \pm 0.5 \mathrm{~mL}^{-1}$ & 2.00 & $3.40 \pm 0.14$ & 102 & $10.3 \pm 0.5 \mathrm{~mL}^{-1}$ \\
\hline Norepinephrine hydrochloride injection ${ }^{\mathrm{d}}$ & $1.20 \pm 0.07$ & $1.01 \pm 0.06 \mathrm{~mL}^{-1}$ & 2.00 & $3.10 \pm 0.06$ & 95 & $1.02 \pm 0.07 \mathrm{~mL}^{-1}$ \\
\hline
\end{tabular}

a Average of three measurements \pm standard deviation.

b Guizhou Bailing Pharmaceutical Industries Co., Ltd., China.

c Wuhan Jiuan Pharmaceutical Co., Ltd., China.

d Wuhan Yuanda Pharmaceutical Co., Ltd., China.

tion of ascorbate, dopamine and norepinephrine. Since all these three reductants can react efficiently with the permanganate ions released at the sample-membrane interface to produce the measured potential signals, they would interfere with the detection of each other. Multicomponent analysis of the mixture of these reductants can be made by separation with a column of highperformance liquid chromatograph and subsequent downstream potentiometric measurement of each separated reductant by using the proposed electrode.

\subsection{Applications}

\subsubsection{Analysis of vegetables}

$25 \mathrm{~g}$ of vegetables were cut into small pieces and homogenized with $200 \mathrm{~mL}$ of the carrier solution, then filtered and diluted with the same reagent by a factor of 100 for the analysis of ascorbate. Potentiometric measurement was done for each sample and the analyte concentration was quantified according to the calibration curve of the proposed electrode. The results are shown in Table 3. It can be seen that the results obtained by the proposed method agree well with those obtained by iodimetric analysis [33].

\subsubsection{Analysis of pharmaceutical preparations}

Several commercial vitamin $C$ tablets were weighted and finely pulverized. A portion of the powder was weighted and dissolved in $100 \mathrm{~mL}$ of the carrier solution. After filtering, the solution was diluted by a factor of 500 for the analysis. For the analysis of injection samples, injection solutions were diluted with the carrier solution by factors of 50,000 and 5000 for dopamine and norepinephrine, respective. The results are given in Table 3. Again, the values obtained by the present method agreed well with those obtained by iodimetric analysis.

\section{Conclusions}

In summary, we have developed a new potentiometric sensing scheme based on current-controlled reagent delivery for rapid, reproducible and continuous detection of analytes in FIA. In contrast to the conventional FIA potentiometric sensor format which is applicable only to ionic species, the proposed detection mode allows on-line detection of a wide range of analytes via complexing, redox or enzyme-catalyzed reactions with the reagents released at the sample-membrane phase boundary. Its application to other chemistries is in progress in our laboratory.

\section{Acknowledgements}

This work was financially supported by the Outstanding Youth Natural Science Foundation of Shandong Province (JQ200814), the Hundred Talents Program of the Chinese Academy of Sciences, the National Natural Science Foundation of China (20977073) and the Taishan Scholar Program of Shandong Province.

\section{References}

[1] M. Trojanowicz, M. Szewczynska, M. Wcislo, Electroanalysis 15 (2003) 347-365.

[2] M. Trojanowicz, Anal. Chim. Acta 653 (2009) 36-58.

[3] M. Trojanowicz, P.W. Alexander, D. Brynn Hibbert, Anal. Chim. Acta 370 (1998) 267-278.

[4] H. Ibrahim, Y.M. Issa, H.M. Abu-Shawish, Anal. Lett. 38 (2005) 111-132.

[5] H. Karami, M.F. Mousavi, M. Shamsipur, Talanta 60 (2003) 775-786.

[6] K. Itai, H. Tsunoda, Clin. Chim. Acta 308 (2001) 163-171.

[7] M. Bralic, E. Generalic, S. Krka, Anal. Lett. 33 (2000) 1811-1825.

[8] M. Bralic, S. Brinic, E. Generalic, L. Vrsalovic, Talanta 63 (2004) 777-783.

[9] Z.L. Chen, M.A. Adams, Talanta 47 (1998) 779-786.

[10] C.G. Amorim, A.N. Araujo, M.C.B.S.M. Montenegro, Talanta 72 (2007) 1255-1260.

[11] A.P.G. Gervasio, E.P. Borges, E.A.G. Zagatto, B.F. Reis, R.A.S. Lapa, J.L.F.C. Lima, J. Agric. Food Chem. 50 (2002) 74-77.

[12] M.C.B.S.M. Montenegro, M.G.F. Sales, J. Pharm. Sci. 89 (2000) 876-884.

[13] P.W. Alexander, P.R. Haddad, G.K.C. Low, C. Maitra, J. Chromatogr. 209 (1981) 29-39.

[14] P.W. Alexander, P.R. Haddad, M. Trojanowicz, Anal. Chem. 56 (1984) 2417-2422.

[15] P.W. Alexander, C. Maitra, Anal. Chem. 53 (1981) 1590-1594.

[16] P.W. Alexander, M. Trojanowicz, P.R. Haddad, Anal. Lett. 17 (1984) 309-320.

[17] E. Bakker, Sens. Actuat. B - Chem. 35 (1996) 20-25.

[18] H.M. Guo, T.J. Yin, Q.M. Su, W. Qin, Talanta 75 (2008) 851-855.

[19] J.W. Ding, W. Oin, Electroanalysis 21 (2009) 2030-2035.

[20] J.W. Ding, W. Qin, Chem. Commun. 97 (2009) 1-973.

[21] J.W. Ding, W. Qin, J. Am. Chem. Soc. 131 (2009) 14640-14641.

[22] D.L. Hall, P.L. Darke, J. Biol. Chem. 270 (1995) 22697-22700.

[23] O.L. Raber, J. Gen. Physiol. 2 (1920) 535-539.

[24] E. Bakker, J. Electrochem. Soc. 143 (1996) L83-L85.

[25] I. Bedlechowicz-Sliwakowska, P. Lingenfelter, T. Sockalski, A. Lewenstam, M. Maj-Zurawska, Anal. Bioanal. Chem. 385 (2006) 1477-1482.

[26] E. Bakker, E. Pretsch, Trac-Trends Anal. Chem. 24 (2005) 199-207.

[27] A. Shvarev, E. Bakker, J. Am. Chem. Soc. 125 (2003) 11192-11193.

[28] A. Vig, A. Igloi, N. Adanyi, G. Gyemant, C. Csutoras, A. Kiss, Bioprocess Biosyst. Eng. 33 (2010) 947-952.

[29] A.F. Danet, M. Badea, H.Y. Aboul-Enein, Luminescence 15 (2000) 305-309.

[30] M. Cheregi, A.F. Danet, Anal. Lett. 30 (1997) 2625-2640.

[31] M. Cano, B. Palenzuela, J.L. Avila, R. Rodriguez-Amaro, Electroanalysis 19 (2007) 973-977.

[32] Z.E. Seckin, M. Volkan, Anal. Chim. Acta 547 (2005) 104-108.

[33] M.Z. Barakat, S.K. Shehab, N. Darwish, A. Elzoheir, Anal. Biochem. 53 (1973) 245-251. 